\title{
The Challenge of Reducing Food Carbon Footprint in a Developing Country
}

Oyenike Mary Eludoyin*

Department of Geography and Planning Sciences, Adekunle Ajasin University, Akungba-Akoko, Nigeria

\begin{abstract}
Reducing the contribution to the greenhouse gases through modification of lifestyles has been the recent focus of geoengineering and climate change discussion. However, many developing countries still have to face the challenge of ensuring food security, and increasing energy availability. This study is an expository review of the impact of food production and peoples' attitudes to food in the face of climate change. The main objective of the study was to examine the sources and dimensions of food carbon footprints, with a focus on Nigeria, and with the view of making recommendations for reduction of greenhouse gasses from food sources. The study argued the need for infrastructural and welfare improvement, and rural development to channel the focus of the people towards environmental preservation and sustenance.
\end{abstract}

Keywords: Food carbon footprint; Climate change; Food production

\section{Introduction}

Sources of $\mathrm{CO}_{2}$ and other greenhouse gases are diverse, and are both natural and anthropogenic. Anthropogenic sources of greenhouse gases are generally becoming a threat to humankind as the earth's temperature increases [1]. For a long time, Increasing industrialization and urbanization were often the targeted anthropogenic sources of greenhouse gases [2]. Recently however, approach to meeting the Climate Change Act target of $80 \%$ cut in greenhouse gases (GHGs) by 2050, in many developed countries, especially in Europe and Americas has shifted to commitment on farming and food [3], alternative energy use, especially as global population rises [4,5]. Convery and Redmond [6] noted that increase in food consumption in the European Union alone may account for about a third increase in carbon footprint in the region by consumers. In most developing countries, records of consumptions are scarce because of poor carbon accounting systems in these countries (if any awareness). Most developing countries are known to rapidly increase in population and contribute significantly to the greenhouse emission through high carbon emitting activities such as use of domestic fuel wood, gas flaring, transportation among others. The study focuses on Nigeria, where most people (at least $60 \%$ of both rural and urban settlers) are meat lovers. Meat lovers emit the largest (3.3 $\mathrm{t} \mathrm{CO}_{2} \mathrm{e} /$ person) per diet (Figure 1).

\section{Aim and Objective}

The aim of this study is to contribute to discussion on the importance of food production and consumption on climate change. Specific objective is to examine the sources and dimensions of food carbon footprints, with a focus on Nigeria, and with the view of making recommendations for reduction of greenhouse gasses from food sources.

\section{Information about Nigeria}

Nigeria is a sub-Saharan African country with population of more than 150 million and population growth of $2.5 \%(1.8 \%$ in the rural areas, and $3.8 \%$ in urban areas) [7]. It is located on $4-14^{\circ} \mathrm{N}$ and $3-15^{\circ} \mathrm{E}$ in the southeastern edge of the West African region, with a land area of about $923800 \mathrm{~km}^{2}$ (14\% of West Africa). Nigerian climate is diversified (Figure 2), and supports growth of many agricultural products, especially tree crops, including fruits, most of which are characterised by high carbon contents.

The tropical rainforest climate, designated by the Koppen climate classification as 'Af, characterises the southern Region, and it is subgrouped into the tropical wet and tropical wet and dry climates as with distance away from the Atlantic Ocean. The tropical rainforest is characterized by small temperature range $\left(26-27^{\circ} \mathrm{C}\right)$ throughout the year, and usually convectional storms, as a result of its proximity to the equatorial climate. This region is known for agricultural practices, especially crop production. The tropical savanna climate exhibits a wellmarked single peak rainy season and a dry season. Mean temperature in the savanna is between 26 and $28.2^{\circ} \mathrm{C}$ throughout the year. Dairy farming and vegetable cultivation are dominant agricultural practices in the savanna, especially in the Guinea and Sudan savanna $[8,9]$. Food cultivation in Nigeria is essentially limited by poor technological infrastructure, and this accounts for large proportion of subsistence agriculture practices in the country.

\section{Food Production Chain and Associated Carbon Sources}

Figure 3 is a conceptualized form of food production processes. The first stage of food production involves cultivation of food crops and rearing of livestock.

\section{Farming activities and release of carbon}

Energy is consumed during the activities involved in agriculture, hence they contribute substantially to carbon footprint. Livestock farming releases methane $\left(\mathrm{CH}_{4}\right)$, and nitrous oxides are often emitted from fertilised fields [3]. Other sources of carbon is the emission from tractor based machines used for tillage, and the soil carbon turnover during tillage and crop planting. The soil carbon stock is large (mean \pm standard deviation in Europe; $20 \pm 12,57 \pm 34$ and $10 \pm 9 \mathrm{~g} \mathrm{Cm}^{-2}$ $\mathrm{yr}^{-1}$ from forest, grassland and cropland, respectively) [10], and the distribution is often affected by changes in vegetation and plant growth,

*Corresponding author: Oyenike Mary Eludoyin, Department of Geography and Planning Sciences, Adekunle Ajasin University, Akungba-Akoko, Nigeria, Tel: +2348037775506; E-mail: baynick2003@yahoo.com

Received August 27, 2014; Accepted December 28, 2014; Published December 30, 2014

Citation: Eludoyin OM (2015) The Challenge of Reducing Food Carbon Footprint in a Developing Country. J Climatol Weather Forecasting 3: 124. doi:10.4172/2332 2594.1000124

Copyright: () 2015 Eludoyin OM. This is an open-access article distributed under the terms of the Creative Commons Attribution License, which permits unrestricted use, distribution, and reproduction in any medium, provided the original author and source are credited. 
Citation: Eludoyin OM (2015) The Challenge of Reducing Food Carbon Footprint in a Developing Country. J Climatol Weather Forecasting 3: 124. doi:10.4172/2332-2594.1000124

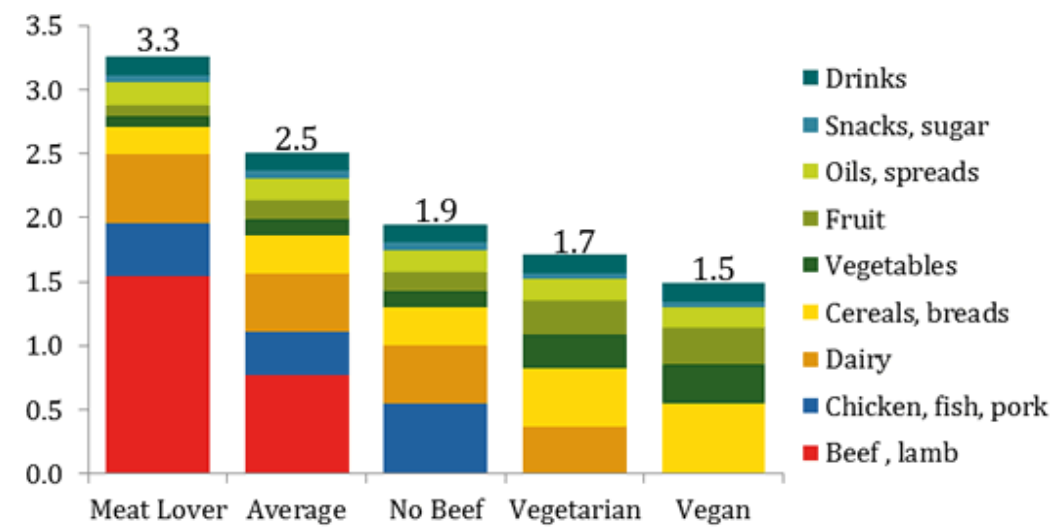

Figure 1: A graphical representation of the amount of $\mathrm{CO}_{2}\left(\mathrm{t} \mathrm{CO}_{2}\right.$ e) emission per person by diet type (http://www.csag.uct.ac.za/2014/02/17/sweating-for-carbonredemption/).

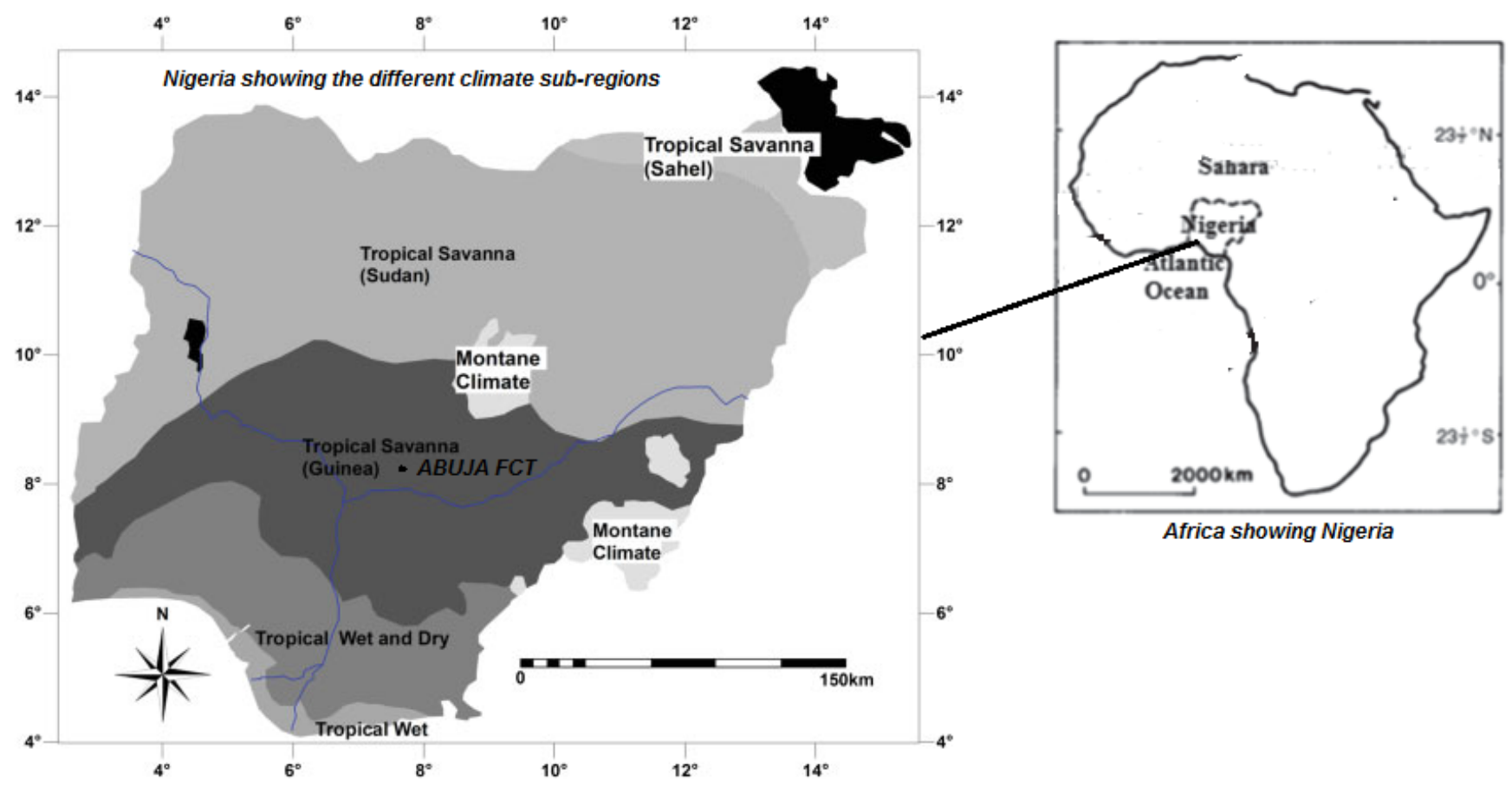

Figure 2: Map showing the different climate sub-regions in Nigeria. Inset is a map of Africa showing the location of Nigeria.

removal of biomass by harvest, and mechanical soil disturbances such as plowing [11].

\section{Food processing}

Activities involved in food processing or refining into supermarket and/or consumption-ready products are also tangible sources of carbon into the environment. Often times, meat are frozen or oven-dried. In West African countries, and importantly in Nigeria, smoked fish and 'Suya', a spicy kebab-like skewered meat (beef, ram and chicken) are popular street foods [12] Preparation of Suya and other skewered meat involves significant use of charcoal, coal or fuel wood, which are important sources of carbon.

A number of studies have shown that fuel wood is an important energy source for food processing in developing countries, including
Nigeria, especially in the rural areas [13-17]. Fuel wood consumption in Nigeria is estimated at about $87 \%$ of the total energy, and it is mostly used irrespective of the economic status of the people [16,18] (Figure 4). The Nigerian Bureau of Statistics, NBS (2007) [19] estimated that the fuel wood use as energy varied from $55 \%$ in the southwest to about $96 \%$ in the north east (95\% in Northwest, $86 \%$ in north central, $78 \%$ in southeast and $73 \%$ in the south-south) an in direct correlation with the poverty rate in the regions.

\section{Food distribution}

Food distribution involves transportation of food crops from the farms to where they are processed. In general, transportation and wastages from food distribution are main sources of carbon release. In Nigeria, and developing countries in general, food transport can occur in different forms: 


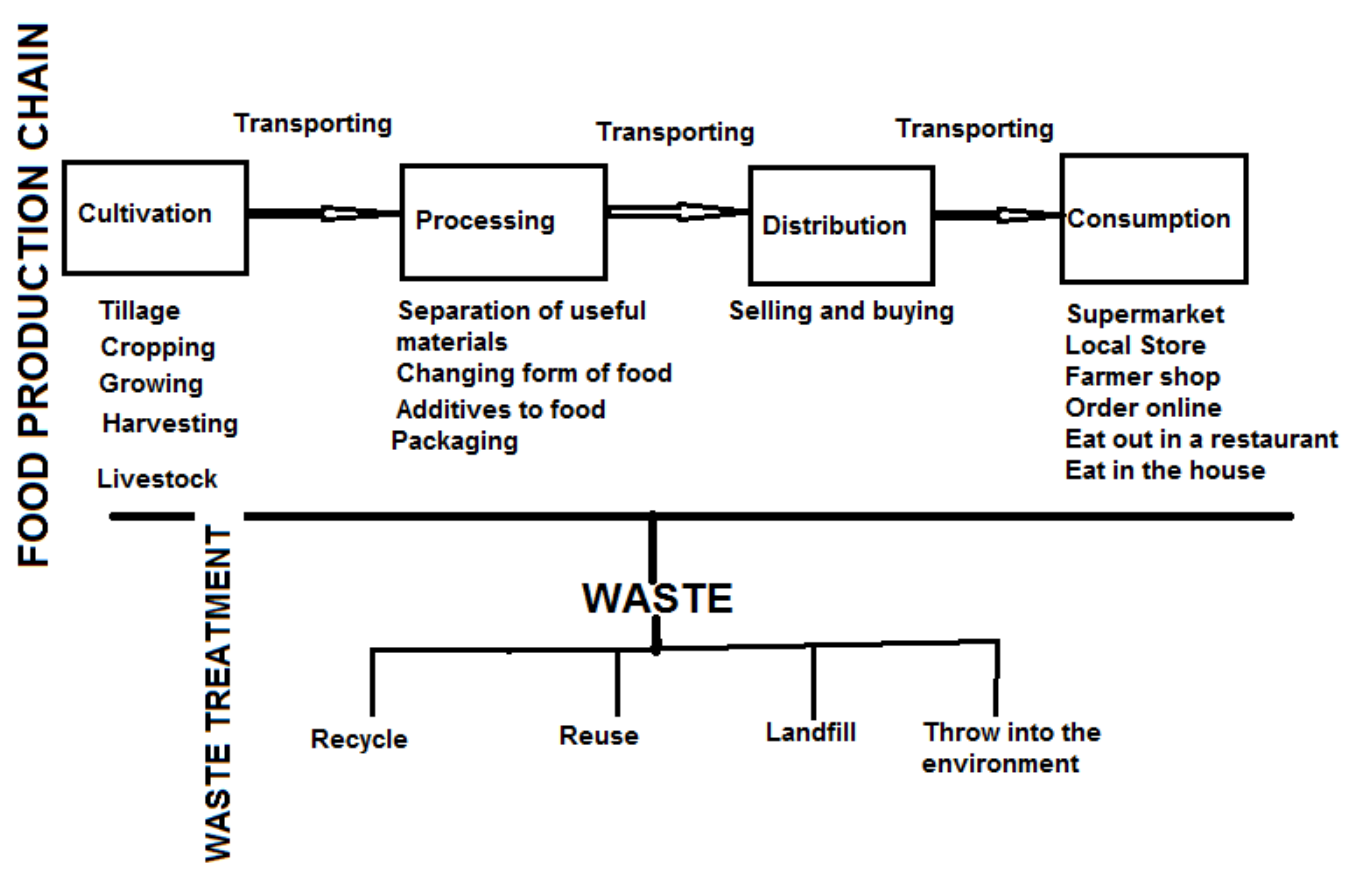

Figure 3: Food production chain and waste generation are important contributors to food carbon footprint.

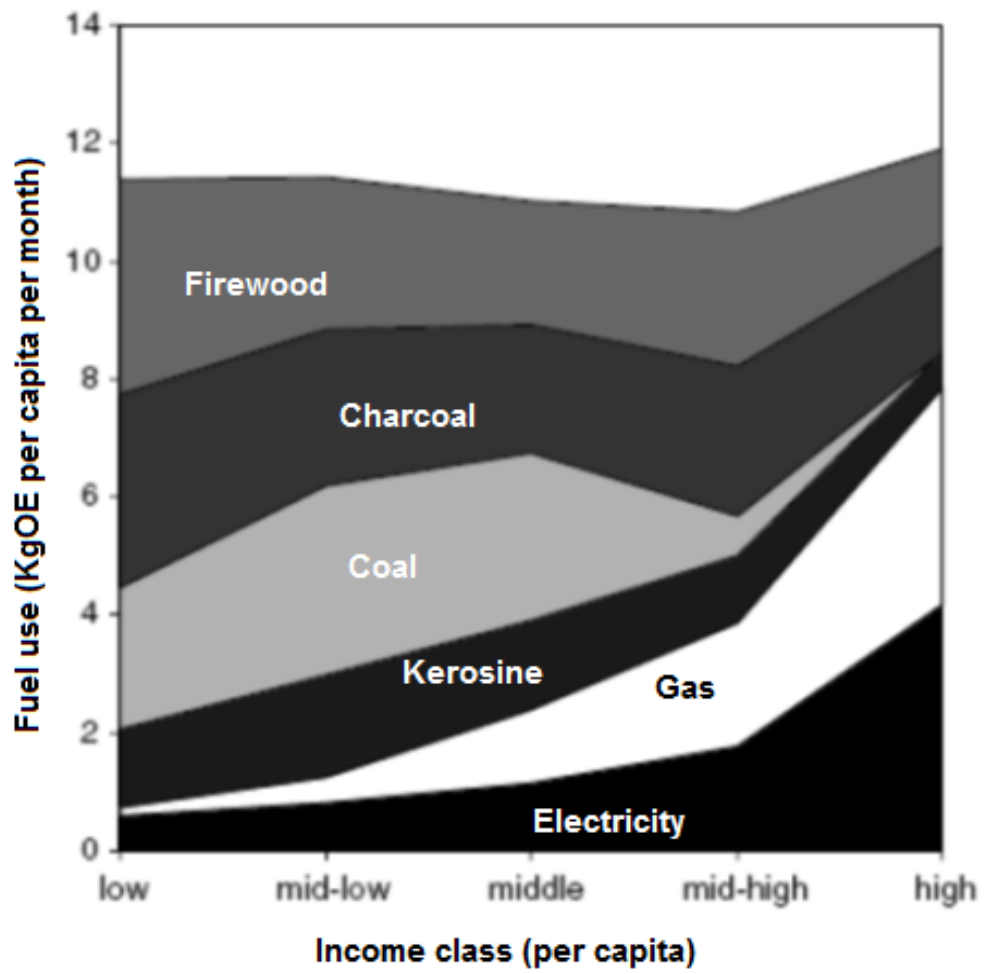

Figure 4: Carbon-rich sources of energy use among people as explained by the energy ladder concept of Arnold et al. [16].

(1) Food products can be sold in open rural food markets. This often involves sales of raw, unpackaged food, and are usually in the rural areas. It also involves sale of vegetable, meat (usually bush-meat such as squirrels, rabbits, grasscutters) and fruits. Food items offered for sale in these markets are usually degradable items because of poor energy and technology for preservation. The markets are often organized daily or four to five days intervals. Unsold degradable items are often left in the market or thrown away to rot in the environment, where they release their carbon contents. 
(2) Larger and more organized markets are transacted at longer day interval, weekly or fortnightly, and are often located within or close to urban settlements. Processed, packaged (local and imported) food stuffs are often sold in these urban markets. Unlike the rural markets, these markets are usually provided with basic amenities, including toilets and water supply, although studies [20] have shown that the infrastructure are often dysfunctional. This kind of market generates a large amount of waste, emerging from sale remnant or packaging.

(3) 'Sabo' is characteristically northern Nigerians food market structure in other parts of Nigeria (south, west and east), where food crops (such as vegetable, yam, potatoes) and livestock are offered for sale. Food and animal products into Sabo markets in the southern Nigeria from the northern parts often involve a long journey in diesel or petrol-powered-trucks.

\section{Food consumption}

Food type and rate of consumption in Africa vary with location, socio-economic status, believe and interaction of individual or community with the western culture. Due to poor food technology, most food and fruits are seasonally consumed. Based on location, rural dwellers generally tend to consume less processed (and more of natural) food than the urban dwellers, and some fruits are more consumed in a season than another season (large quantities of fruits are wasted immediately after their harvest time in the wet season, than in the dry season) because of poor technology for preservation. Electricity supply in most rural areas in Nigeria is low, and almost nonexistence [20].

Most people in the high socio-economic status in Africa often prefer to live in the urban areas, and a large proportion of these people consume significant amount of processed foods, such as noodles and processed drinks. Fast food joints such as 'Mr Biggs', 'Chicken Republic', 'Captain Cook', etc. are major characteristics of the Nigerian urban area, and the frequency of visit to these 'joints' is often directly related to the socio-economic status of an average urban Nigerian. Visitors to these places also often do so in their cars because typical Nigerians' socio-economic status is often considered as equal to the number of cars they flaunt.

\section{Waste}

Food wastes in Nigeria and most developing countries is a major source of carbon to the environment. From cultivation or rearing of livestock, to the period of consumption, wastes are generated. The lifestyle of most Nigerians is also a contributing factor in the amount of wastes generated. Processed foods in many capital cities in Nigeria, especially in the Federal Capital City, Abuja and among the very affluent people often contradicts the law of demand (the higher the price, the lower the demand), as consumers tend to consume more at higher price because of the general perception that such attitude can show their economic 'status'. Unlike many developed countries where unused household materials can be donated to Gift and charity shops or packaged for recycle, most unused materials in Nigeria are thrown away without proper management. Most existing landfills are also rarely protected [21], and they are therefore sources of environmental pollution, releasing $\mathrm{CO}_{2}$ and methane. Poor electricity power supply, very low re-use, preservation and recycle innovations, poor or nonexistent charity shops are major encouragers of food waste in Nigeria, and these often apply to most developing countries.

\section{Conclusion and Recommendations}

The main objective of this study was to examine the sources and dimensions of food carbon footprints, and made specific reference to Nigeria as a typical example of most developing countries. The study indicated that large sources of carbon occurred at the various stages of agriculture production and consumption, and that climate education, peoples' lifestyle, technology and approach to waste management are main determinants of the extent of carbon footprints. The study concluded that although food security is a major problem in developing countries, variations in the rural-urban and poor-rich dichotomies in infrastructure and lifestyle or tastes are important challenges facing the carbon footprint reduction in Nigeria. The study recommends change in the feeding habit of people from carbon-rich foods to less of carbon rich foods. It also recommends processes or innovations for reducing food wastages.

\section{References}

1. Le Treut H, Somerville R, Cubasch U, Ding Y, Mauritzen C et al. (2007) Historical overview of climate change. Earth 1: 93-127.

2. Boko M, Niang I, Nyong A, Vogel C, Githeko A et al. (2007) Climate change 2007 impacts, adaptation and vulnerability. In: Parry ML et al. (eds.), Contribution of working group II to the fourth assessment report of the intergovernmental panel on climate change. University Press, Cambridge, UK, pp. 433-467.

3. Soil Association (2009) Soil carbon and organic farming, Scotland, pp. 212.

4. Thies PR, Flinn J, Smith GH (2009) Is it a showstopper? Reliability assessment and criticality analysis for Wave Energy Converters, Proceedings of the 8th European Wave and Tidal Energy Conference, Uppsala, Sweden.

5. Thies PR, Johanning L, Smith $\mathrm{GH}$ (2011) Towards component reliability testing for marine energy converters. Ocean Engineering 38: 360-370.

6. Convery FJ, Redmond L (2007) Market and price developments in the European Union emissions trading scheme. Review of Environmental Economics and Policy 1: 88-111.

7. United Nations Statistics Division (2013) World Statistics Pocketbook, Country Profile, Nigeria.

8. Ileoje NP (2001) A New Geography of Nigeria. New Revised Edition, Longman Publishers: Ibadan, Nigeria.

9. Eludoyin OM, Adelekan IO, Webster R, Eludoyin AO (2014) Air temperature relative humidity, climate regionalization and thermal comfort of Nigeria. International Journal of Climatology 34: 2000-2018.

10. Schulze ED, Luyssaert S, Ciais $P$, Freibauer A, Janssens IA (2009) Importance of methane and nitrous oxide for Europe's terrestrial greenhouse-gas balance. Nature Geoscience 2: 842-850.

11. Schrumpf M, Schulze ED, Kaiser K, Schumacher J (2011) How accurately can soil organic carbon stocks and stock changes be quantified by soil inventories? Biogeosciences 8: 1193-1212.

12. Ekanem EO (1998) The street food trade in Africa: safety and socioenvironmental issues. Food Control 9: 211-215.

13. Gustafon D (2001) The role of wood fuels in Africa. In: N Wamukonye (ed.) Proceeding of a high level regional meeting on energy and sustainable development. Food and Agriculture Organization of the United Nations, Rome, pp. 99-101.

14. Girard P (2002) Charcoal production and use in Africa: What Future? Unasylva 211: 30-34.

15. Ogunsawa OY, Ajala OO (2002) Firewood crises in Lagos- implication on the suburban and rural ecosystem management. In: Abu JE, Oni PO and Popoola $L$ (eds.), Proceeding of the 28th annual conference of Forestry Association of Nigeria at Akure, Ondo State, pp. 257-264

16. Arnold MJE, Kohlin G, Persson R (2006) Woodfuels, Livelihoods, and Policy Interventions: Changing Perspectives. World Dev 34: 596-611.

17. Zaku SG, Kabir A, Tukur AA, Jimento IG (2013) Wood fuel consumption in Nigeria and the energy ladder: A review of fuel wood use in Kaduna State. Journal of Petroleum Technology and Alternative Fuels 4: 85-89.

18. The Solar Cooking Archive (2011) Fuel wood as percentage of energy consumption in developing countries. 
Citation: Eludoyin OM (2015) The Challenge of Reducing Food Carbon Footprint in a Developing Country. J Climatol Weather Forecasting 3: 124. doi:10.4172/2332-2594.1000124

Page 5 of 5

19. National Bureau of Statistics (2007) Annual abstracts of statistics, Abuja, Nigeria.

20. Allen AA (2013) Population dynamics and infrastructure: meeting the millennium development goals in Ondo State, Nigeria. African Population Studies 27: 224229.
21. Oyeku OT, Eludoyin AO (2010) Vulnerability of groundwater resources to heavy metal contamination in a Nigerian urban settlement. African Journal of Environmental Science and Technology 4: 201-204.

Citation: Eludoyin OM (2015) The Challenge of Reducing Food Carbon Footprint in a Developing Country. J Climatol Weather Forecasting 3: 124 doi:10.4172/2332-2594.1000124 